\title{
Reflexões sobre o processo educativo em tempos de pandemia através das percepções de pós-graduandos em educação
}

Reflections on the educational process in times of pandemic through the perceptions of graduate students in education

\author{
Jacks Richard de Paulo (은 http://orcid.org/0000-0003-1200-5346 \\ Universidade Federal de Ouro Preto (UFOP) \\ e-mail: jacks@ufop.edu.br
}

Stela Maris Mendes Siqueira Araújo (1) https://orcid.org/0000-0002-8910-2542

Instituto Federal de Minas Gerais (IFMG), campus Ribeirão das Neves

e-mail: stela.araujo@ifmg.edu.br

Priscila Daniele de Oliveira (는 https://orcid.org/0000-0002-3435-7812

Universidade Federal de Ouro Preto (UFOP)

e-mail: pdoliveira20@gmail.com

\section{Resumo}

Esta pesquisa foi desenvolvida com o intuito de refletir sobre a situação e desdobramentos do período de oferta de ensino remoto emergencial devido ao COVID19 a partir da percepção de alunos de mestrado e doutorado na área de educação, matriculados em uma instituição pública de ensino, situada no interior do estado de Minas Gerais - Brasil. Para tal, efetuou-se uma revisão junto à literatura acadêmica que trata sobre a temática investigativa, para compreender as peculiaridades das percepções e analisá-las à luz da literatura. Os dados foram obtidos através de uma entrevista virtual com o intuito de potencializar a diálogo com os discentes e com o propósito de coletar informações sobre a percepção dos alunos em relação à experiência vivenciada com o ensino remoto emergencial. Os dados da pesquisa revelaram que as percepções convergem no sentido de que as tecnologias podem contribuir para a aprendizagem, principalmente, no contexto atual de pandemia. Por fim, demonstrou-se também por meio da percepção discente que tais recursos tecnológicos não são capazes de suprimir por completo os espaços de socialização característicos do ensino presencial.

Palavras-chave: Acesso à Tecnologia. Aprendizagem. Internet. Percepção da fala.

\section{Abstract}

This research aims to reflect on the situation and developments in the period of emergency remote education provision due to Covid-19 from the perception of 
master's and doctorate students in the field of education, enrolled in a public education institution, located in the interior of the state of Minas Gerais - Brazil. To this end, a review was carried out with the academic literature dealing with the investigative theme, seeking to understand the peculiarities of perceptions and analyze them in the light of literature. The data was obtained through a virtual interview to enhance the dialogue with the students to collect information on the perception of the students about to the experience of remote emergency teaching. The research data revealed that perceptions converge in the sense those technologies can contribute to learning, especially in the current pandemic context. Finally, it was also demonstrated through student perception that such technological resources are not capable of completely suppressing the socialization spaces characteristic of face-to-face teaching.

Keywords: Access to the technology. Learning. Internet. Perception of speech.

\section{Introdução}

A situação de pandemia ocasionada pelo novo Coronavírus, ainda em curso, tem sido responsável por inúmeras mortes, além de impactar todos os setores e esferas da sociedade. Os desdobramentos da pandemia geraram uma situação inusitada para sociedade e também revelaram um despreparo da humanidade para lidar com uma situação tão adversa para o contato entre as pessoas nas relações cotidianas e que paira a nível global. No caso da educação, em específico, há que se considerar um (re)direcionamento sobre as novas formas tanto de ensinar quanto de aprender, midiatizadas por meio de tecnologias e que passa a ganhar destaque nesse novo contexto de pandemia da história de evolução da humanidade.

Inexoravelmente, o distanciamento social passa ser uma prioridade, emergindo a possibilidade de uso das tecnologias tanto no cenário educacional quanto nas relações de trabalho como forma de se evitar o contágio. Dito posto, pode-se inferir que as limitações frente ao uso de tais ferramentas com cunho pedagógico têm evidenciado que o sistema educacional brasileiro, demanda tanto infraestrutura quanto sólida formação para mediar os processos de ensino e de aprendizagem. No entanto, apesar das limitações ressaltadas, diferentes instituições e níveis de ensino em todo o mundo vêm fazendo uso de tecnologias para o processo de construção de conhecimento dos alunos e também enquanto uma forma de se evitar que as atividades escolares sejam interrompidas.

Esta pesquisa foi desenvolvida no âmbito no Grupo de Pesquisa sobre Tecnologias em Educação (TECNOGEO), da Universidade Federal de Ouro Preto, do departamento de Educação/ICHS, (Instituto de Ciências Humanas e Sociais) sob o intuito de refletir sobre a percepção dos discentes do programa de pós-graduação em educação sobre o Ensino Remoto Emergencial.

A pesquisa em questão foi desenvolvida com cunho de natureza qualitativa. Para alcançar os objetivos nesta investigação, inicialmente, realizou-se uma 
revisão junto à literatura acadêmica que trata sobre os desafios e dos processos de construção do conhecimento em tempos de pandemia do COVID19.

A pandemia do COVID19 é um caso raro, por isso optou-se pela metodologia do estudo de caso, segundo Yin (2005) a pesquisa na forma de estudo de caso inclui casos únicos e casos múltiplos - ambos como variantes dos projetos de estudo de caso. O autor considera que o estudo de caso único é eminentemente justificável quando representa uma circunstância rara ou exclusiva, como o atual momento em que o ensino remoto emergencial acontece.

Segundo Yin (2005), em geral, os estudos de caso representam a estratégia preferida quando se colocam questões do tipo "como" e "por que". Isso ocorre quando o pesquisador tem pouco controle sobre os acontecimentos e quando o foco se encontra em fenômenos contemporâneos inseridos em algum contexto da vida real.

Em seguida, para levantar os dados para este estudo de caso desenvolveu-se a etapa de um diálogo virtual com nove (9) discentes do Programa de pósgraduação, mestrado e doutorado de uma Universidade Federal localizada no interior do estado de Minas Gerais. Para a realização da entrevista, utilizou-se o Google Meet que é uma plataforma que permite reunir virtualmente. Para o momento dos encontros virtuais, que foram realizados individualmente com cada participante da pesquisa, o diálogo se fez presente com o intuito de conhecer esta realidade e dar voz aos estudantes. Saber se eles estavam preparados, dialogar sobre como eles percebem o ensino remoto emergencial com o propósito de refletir sobre esse momento.

Diante dessa situação ainda pouco conhecida, que acaba por gerar questionamentos por parte de professores, alunos e toda comunidade escolar. Portanto, cabem várias considerações. Dentre elas, a necessidade de se refletir sobre quais são as percepções dos discentes de um programa de pósgraduação em educação (mestrado e doutorado) apresentam em relação ao desenvolvimento do Ensino Remoto Emergencial.

\section{Fundamentação teórica}

O contexto atual causou grandes reviravoltas em diversos setores, formas de trabalho, atendimento, produção e transporte passaram por mudanças e até reinvenções. Na área educacional não foi diferente, uma forma de ensino que tinha opiniões bem divididas, tem assumido o momento como saída regular, o Ensino Remoto, ou melhor, adequá-lo para o momento da pandemia do COVID19.

Em todo esse mar de mudanças e adequações, muitos termos se fazem presentes e podem ser confundidos também. Um exemplo é pensar o Ensino Remoto Emergencial (ERE) como sinônimo do Ensino à Distância (Ead). De acordo com Garcia et al. (2020, p. 05), tem-se que:

Ensinar remotamente não é sinônimo de ensinar a distância, embora esteja diretamente relacionado ao uso de tecnologia e, nesse caso, digital. O ensino remoto permite o uso de plataformas já disponíveis e abertas para outros fins, que não sejam estritamente os educacionais, 
assim como a inserção de ferramentas auxiliares e a introdução de práticas inovadoras. A variabilidade dos recursos e das estratégias bem como das práticas é definida a partir da familiaridade e da habilidade do professor em adotar tais recursos.

Mesmo que o momento atual seja totalmente inclinado para o distanciamento, o ERE conta com a presença digital do professor e dos estudantes em uma aula online, no sentido de se projetar a conhecida presença física por meio da tecnologia. E, cabe destacar que este foi um molde "emergencial", que não teve um período gestacional planejado em longos períodos de tempo.

Acredita-se que o fato que leva a esta confusão, é o fato dessas modalidades de ensino terem em comum o distanciamento e a aprendizagem. Mas, sobre a EaD, em concordância com o Decreto $n^{\circ} 2.494$ da Presidência da República, que regulamenta o artigo 80 da Lei de Diretrizes e Bases da Educação Nacional (LDB), tem-se:

\begin{abstract}
A Educação a Distância é uma forma de ensino que possibilita a autoaprendizagem, com a mediação de recursos didáticos sistematicamente organizados, apresentados em diferentes suportes de informação, utilizados isoladamente ou combinados, e veiculados pelos diversos meios de comunicação (BRASIL, 1998).
\end{abstract}

Logo, se configura como algo já pensado para este formato remoto, ou seja, se diferir do modelo presencial. Ademais, sabe-se que em decorrência de diversos aspectos, nosso país ainda não tem efetividade em garantir ensino superior para toda ou pelo menos grande parte da população. A partir desta premissa, a Educação à Distância vem como oportunidade democrática, que tem atuado para tentar encurtar essa distância entre o "querer" e o "não conseguir" se matricular e se formar em um curso de ensino superior.

Este tipo de modalidade que tenta ultrapassar as barreiras da distância, tem seus prós e seus contras, como tudo na vida. Para grande parte da população, predomina a concepção de que a educação a distância, ao contrário do ensino presencial, não contribui para a efetiva aprendizagem por diferentes motivos. $E$ talvez, pela existência dessas opiniões, o ERE seja também colocado como negativo.

Um aspecto que une as duas modalidades de ensino, é o uso da tecnologia. Convém-se destacar que esta ganhou papel primordial diante do objetivo de dar continuidade ao ensino neste frágil momento, e assim encurtar as distâncias físicas e fortalecer a aprendizagem e a comunicação entre instituição, professores e alunos.

Com base em diversos avanços, pode-se afirmar que a sociedade atual é bastante tecnológica, ou melhor, boa parte. $\mathrm{E}$ isso não se restringe a apenas celulares, computadores ou televisões de última geração, se refere a uma infinidade de outros equipamentos eletrônicos, aplicativos, softwares que nos permitem colocar em prática uma série de verbos, como: resolver, informar, comprar, pagar com poucos cliques. Dessa forma, pensa-se que não seja mais possível desvincular a educação do uso das tecnologias. 
Quando se pensa nas mudanças que ocorreram no decorrer das décadas, vêse que o processo de ensino e de aprendizagem também passou por intensas mudanças. Antigamente, tinha-se a memorização como forma de aprender e o papel do professor era apenas de um transmissor do conhecimento. Atualmente essas relações mudaram, o professor é visto como um mediador e facilitador do processo de ensino e de aprendizagem, principalmente, destacando-se a figura dos alunos como sujeitos ativos dentro desse processo. Nesse sentido, (VYGOTSKY 2001), afirma que sobre o professor recai um novo papel importante, na medida que ele ocupa o papel de mediador da aprendizagem, destaca-se sua importância nos processos de ensino e de aprendizagem, sobretudo, de produção de conhecimento.

Com o propósito de endossar ainda mais essas mudanças, faz-se necessário uma maior adesão aos recursos que transformem as aulas, de modo a instigar mais e mais os alunos. Para isso, tem-se a internet como um outro termo de grande importância. Assim, "a "internet" é um espaço possível de integração e articulação de todas as pessoas conectadas com tudo que existe no campo digital, o ciberespaço" (KENSKI, 2012, p. 34). E hoje, praticamente tudo o que precisa é encontrado neste espaço, a internet.

Pode-se citar uma infinidade de tecnologias que podem ser boas aliadas ao ensino, proporcionando interação e articulação do conhecimento, para tornar a aprendizagem mais interessante, por exemplo, TV, DVD, câmeras, data show, rádio, computador, projetor, internet, aplicativos, redes sociais como Facebook, Instagram, Whatsapp e etc. De acordo com Polato (2009), o simples fato de se argumentar a respeito da união entre tecnologia e conteúdos pode vislumbrar um universo de oportunidades para o ensino. Nesse sentido, cabe destacar que é a partir dela que tem se conseguido enfrentar os desafios atuais em termos de distanciamentos geográficos.

As faces positivas do uso das tecnologias são visíveis nas proposições de vários autores, conforme Sancho e Hernándes et al. (2006, p. 88)

[...] o uso das tecnologias é visto como um meio para fortalecer um estilo mais pessoal de aprender em que os estudantes estejam ativamente envolvidos na construção do conhecimento e na busca de respostas para seus problemas específicos.

Assim, os alunos podem adensar cada vez mais suas habilidades para aprender sobre as tecnologias. Já para Mainart e Santos (2010), é fundamental a utilização das tecnologias no ambiente escolar, pois esse é um local para a construção do conhecimento, para a socialização do saber, um local de discussão, de troca de experiências e desenvolvimento de uma nova sociedade.

São extremamente notáveis os benefícios da tecnologia aliados à educação, porém este é um assunto que possui muitas discussões. Uma delas se pauta no fato de alguns professores que são interessados na utilização da tecnologia e paralelo a isso, sempre buscam se preparar, conhecer para melhor aplicá-las em sala de aula e por outro lado, aqueles professores que se mostram indecisos e inseguros em relação ao método, chegam até a pensar que tais recursos vão 
substituí-los, o que é um grande equívoco. Segundo Rosales e Magalini (2007, p. 5):

O professor deve ter em mente que a tecnologia vem como um recurso, um suporte a mais para o processo de ensino-aprendizagem, como [...] uma ferramenta de apoio, um instrumento inovador, tornando a aprendizagem mais eficiente e eficaz, e o professor deve estar em [...] processo permanente de aprendizagem e ter uma postura de pesquisador, investigador e crítico.

Dessa maneira, acredita-se que tais mudanças e adequações advêm dos avanços pelo qual passam a sociedade, logo, manter rivalidade ou resistência frente a isso, significa parar no tempo e ao mesmo tempo deixar de apoderarse das riquezas que tais recursos podem representar para o âmbito educacional.

\section{Reflexões acerca dos diálogos}

Os resultados apresentados estão relacionados com a percepção dos discentes quanto ao: acesso e capacitação para o desenvolvimento das atividades online; e a quantidade e a qualidade das demandas que cada disciplina/professor propõe.

Segundo Oliveira e Machado (2004), a percepção é o processo de seleção, organização e interpretação das informações recebidas pelos nossos sentidos para desenvolver a consciência do meio ambiente e de nós mesmos, varia de um indivíduo para outro. Com base nessa analogia, cada um de nós tem percepções diversas, transpassada a objetividade do concreto pelas diferentes subjetividades, resultados e resultantes das interposições individuais e coletivas em suas atitudes. Conforme menciona Tuan (1980, p. 4) "atitude é primeiramente uma postura cultural, uma posição que se toma frente ao mundo. Ela tem mais estabilidade que a percepção e é formada de uma longa sucessão de percepções, isto é, experiências".

Ao analisar os diálogos observou-se que existem percepções convergentes, principalmente, nos aspectos de infraestrutura e capacitação de discentes para lidar com o ensino remoto emergencial. Os discentes que participaram do diálogo conciliam o trabalho com os estudos, sendo que alguns já possuíam experiência com EaD. No que tange ao perfil dos estudantes, mesmo com culturas diferentes, mas que vivenciam esta experiência, esse momento, juntos, possibilita compreender o porquê a maioria das percepções são extremamente semelhantes e convergem para a continuidade das atividades do curso, para não "perder" tempo.

De acordo com Serafini (2012), embora esses dados da pesquisa nos apontem tal interesse por parte dos discentes, não se pode perder de vista a responsabilidade da $\mathrm{EaD}$ em promover a autonomia, condicionada a sua existência, de forma que ela ajude os alunos a desenvolvê-la no decorrer do curso. 
Outro ponto convergente, não necessariamente uma percepção, mas um fato é a questão do acesso à internet. Embora todos já possuíssem acesso à internet, o notebook e celulares, todos citaram o fato da internet ter o acesso lento, o que dificulta os encontros síncronos, pois criam algumas limitações como dito por eles o fato de não poder abrir as câmeras, o microfone tem que ficar desligado para não dar microfonia.

Sobre tal aspecto, de acordo com a base de dados do site do IBGE (Instituto Brasileiro de Geografia e Estatística), viu-se que o número de residências com acessos à internet tem aumentado, porém sobre a qualidade deste acesso, temse que:

Dos 31,2 milhões de domicílios com utilização de Internet em 2013, $2,3 \%$ (725 mil) possuíam exclusivamente a conexão discada, e 97,7\% (30,5 milhões), a conexão em banda larga. A conexão em banda larga fixa estava presente em $77,1 \%$ (24,1 milhões) dos domicílios, e a banda larga móvel, em 43,5\% (13,6 milhões). Em 23,0\% (7,2 milhões) dos domicílios, existiam as duas modalidades de conexão (IBGE, 2015, p. 37).

Ademais, sabe-se que o acesso por conexão discada já se configura como obsoleto, mas ainda a velocidade da banda larga que existe no país é baixa, o que tende a ser um problema diante do formato de ensino do momento.

Ainda, com o propósito de fazer um comparativo com dados mais recentes, a partir de 2018, mesmo diante do aumento do número de acesso à internet, uma a cada quadro pessoas se encontravam "desconectadas" dessas tecnologias, como mostra a pesquisa abaixo:

Os dados, que se referem aos três últimos meses de 2018, mostram ainda que o percentual de brasileiros com acesso à internet aumentou no país de 2017 para 2018 , passando de $69,8 \%$ para $74,7 \%$, mas que 25,3\% ainda estão sem acesso. Em áreas rurais, o índice de pessoas sem acesso é ainda maior que nas cidades, chega a 53,5\%. Em áreas urbanas é 20,6\%. (SITE AGÊNCIA BRASIL, 2020).

Ao somar esses dois percentuais, tanto de áreas rurais, quanto urbanas, temse um total em números de 46 milhões de pessoas sem acesso à internet. Quando se projeta essa realidade para o ano atual, mesmo diante do cenário de aumento do número de desempregados, há aumentos nos acessos, porém percebe-se que não houveram mudanças significativas, ao passo de que, diante de uma pesquisa mostrada pelo site Brasil de Fato (2020), "indica que a cada cinco pessoas, uma afirma que só consegue acessar a internet através da rede emprestada do vizinho". Logo, até o momento é um grande desafio frente as demandas e possibilidades do isolamento social.

Apresentam como expectativas dessa experiência, o aprendizado em aperfeiçoar o uso das tecnologias educacionais, pois o momento é propício para essa aprendizagem. Consideram as ações dos professores bastante pertinentes neste momento, em criar e participar de grupos de WhatsApp, responder e-mail com frequência, ou seja, estarem em dia com as devolutivas quanto às dúvidas, tudo para auxiliar o aluno neste momento de pandemia. 
Outro aspecto semelhante dentro destes diálogos, foi o fato da economia diante do deslocamento que antes era preciso ser feito. Assim, economizam com refeição, transporte e com o tempo entre as residências, ambiente de trabalho e o campus. Pode-se notar que estes são aspectos comuns e indicam que o trabalho remoto pode atenuar grande parte de problemas que permeiam as diferentes realidades. Em conformidade, Pereira (2015, p. 91) aborda em sua pesquisa que para a maioria dos alunos:

[...] o fator tempo foi preponderante, pois os alunos relatam que este se revela como primordial para sua escolha. Estudar no conforto de casa, no horário estipulado por eles, sem a locomoção em meio ao trânsito estressante acresce no seu aprendizado.

Existe em comum, o fato de todos compreenderem que o momento é atípico e que as aulas presenciais fazem muita falta. Consideram que foram prejudicados em parte, pois o contato social e as trocas de experiências podem ser mais potencializadas em aulas presenciais, além do estabelecimento dos círculos de amizade. Tais preceitos podem ser correlacionados com a investigação realizada por Belloni (2009), se não estreitarmos as relações tanto de forma síncrona quanto assíncrona e envolver os processos de interação entre discentes e docente pode gerar uma impressão de solidão nos processos educativos via EaD.

Há aspectos percebidos que divergem no que se refere à demanda da habilidade individual do discente. Em alguns diálogos notou-se a satisfação quanto ao ambiente virtual disposto pela instituição e por outro lado, outros aprenderam mais coisas depois que as primeiras aulas síncronas e atividades aconteceram, além de citarem um forte vínculo em termos de ajuda entre os colegas, tal interação soma-se bastante neste processo. Nesta questão, acredita-se que um maior estreitamento com todas as funcionalidades dos ambientes virtuais seja de extrema importância para a aprendizagem, assim conforme Ribeiro et al (2007, p. 05):

Os ambientes virtuais de aprendizagem agregam várias tecnologias encontradas na Web para provê a comunicação, disponibilização de materiais e administração do curso. $O$ conjunto de funcionalidades que cada ambiente possui é estabelecido pelos requisitos definidos em cada ambiente.

No que tange a quantidade de tempo em que conciliam o trabalho com o estudo, há bastante diferença, alguns mais experientes e outros menos. Paralelo a isso, percebeu-se que tal conjunto de ação se tornou bastante familiar, não gerando tanto cansaço ou desgaste e sim, uma relação de costume e enquanto para outros, ainda se configura como uma tarefa dificultosa. Dessa forma, conforme (GONDIM, 2002, p. 300) tem-se que:

Diante das dificuldades relacionadas ao desgaste físico, à redução de tempo para realização de atividades acadêmicas extraclasse, cansaço, estresse, redução do rendimento acadêmico e hábitos de dormir tarde e se alimentar mal, cabe ressaltar também as vantagens que a conciliação entre as atividades acadêmicas e profissionais possibilitam. Os estudantes veem no trabalho, além do retorno financeiro, a possibilidade de desenvolver as exigências de um perfil 
multiprofissional, sua identidade e a conquista da maturidade pessoal, diante das situações de imprevisibilidade das organizações atuais.

Ainda, sobre passar mais tempo no ambiente domiciliar, mesmo sob a condição benéfica de evitar o deslocamento, alguns relataram que é um excesso que pode gerar cansaço e esgotamento, além de contribuir para a procrastinação. Por outro lado, alguns contemplaram o conforto do lar, como essencial para executar todas as atividades. O aluno busca, na modalidade $\mathrm{EaD}$, encontrar uma solução imediata para conciliar seu trabalho e os demais afazeres com o estudo.

Dialogou-se também sobre o ato de procrastinar, que é muito comum em nossa sociedade atual e pode-se notar nos discursos que a maioria dos entrevistados apostam em técnicas para burlar tal coisa, como leituras de autoajuda, práticas meditativas, terapia com profissional e adoção da agenda de tarefas. De modo geral, a procrastinação é um fenômeno, relativamente, comum entre estudantes, sendo, geralmente, tido como prejudicial à vida acadêmica (SCHOUWENBURG, 2004). E ainda, tem-se que a procrastinação acadêmica nada mais é que "uma manifestação do comportamento procrastinatório no ambiente acadêmico, logo, as causas de natureza comportamental, afetiva e cognitiva que caracterizam o comportamento procrastinador" (FONTES, 2012, p. 35). Mas convêm destacar que este é um assunto que se ramifica em várias outras áreas, sua menção ao trabalho vinculou-se ao fato de aparecer nas trajetórias dos entrevistados.

Outra percepção se refere à maneira que algumas aulas foram conduzidas. Relataram que alguns professores têm se preocupado em passar os conteúdos programáticos independentemente da quantidade de tempo, ou seja, fica cansativo e monótono passar muitas horas atrás de uma tela. $\mathrm{E}$ em outros diálogos, há concordância com os formatos das aulas. Mas, cabe destacar que há uma variedade de professores e disciplinas em voga. Diante do exposto, fazse necessário pensar em metodologias e materiais didáticos que viabilizem esse aprendizado autônomo, tendo o cuidado de não reproduzir as velhas pedagogias com novas tecnologias (BELLONI, 2009).

Diante do atual cenário, achou-se pertinente questioná-los sobre as suas preferências com a perspectiva de futuro. Se caso houvesse possibilidade de continuar seus estudos em EaD, Ensino Híbrido ou o Presencial, foi possível perceber através dos diálogos que alguns priorizam a interação da modalidade presencial sob qualquer circunstância e outros disseram que o Ensino Híbrido é interessante para a graduação e pós-graduação, para evitar que o estudante não necessite estar na instituição em todo o tempo. Portanto, o Ensino Híbrido tem sido aceito por muitos como uma estratégia positiva, ou seja, que se aproxima cada vez mais de uma posição mais centrada no aluno e mais sensível às suas reais necessidades, bem como do contexto em que se insere (DUFFY, 1998).

\section{Considerações Finais}


Na percepção dos discentes, o Ensino Remoto Emergencial (ERE) tem sido uma boa alternativa para o momento em que o distanciamento social faz-se necessário. $E$ que acreditam que será uma oportunidade para potencializar o uso das tecnologias nos processos de ensino e de aprendizagem, em destaque, no ensino presencial.

Percebeu-se também que dentre os aspectos relacionados às percepções do uso das tecnologias voltadas para o ensino se convergem a opinião dos discentes por se tratar de uma circunstância rara. Portanto, outras pesquisas podem e devem ser desenvolvidas para melhor compreensão, no mesmo contexto, mas em realidades diferentes.

Outro fato a ser destacado é que na percepção dos alunos, o espaço físico da universidade é de suma importância para o desenvolvimento das atividades acadêmicas, pelo fato de privilegiar o convívio social e facilitar a aprendizagem. Além deste, posicionam positivamente em relação à adesão do ERE como estratégia para o momento atual.

Diante de tudo, viu-se que as opiniões se aproximam e se diverge dentro de um mesmo contexto, o da pandemia COVID19 no Brasil, o que contribui grandemente para entender aspectos que têm permeado as relações de ensino, especialmente neste momento.

\section{Referências bibliográficas}

AGÊNCIA BRASIL. Um em cada 4 brasileiros não tem acesso à internet,
mostra $\quad$ pesquisa. https://agenciabrasil.ebc.com.br/economia/noticia/2020-04/um-em-cadaquatro-brasileiros-nao-tem-acesso-internet. Acesso em: 17 nov. 2020.

BELLONI, M. L. Educação a distância. 5.ed. São Paulo: Autores Associados, 2009.

BRASIL. Decreto $n^{\circ}$ 2.494, de 10 de fevereiro de 1998. Regulamenta o Art. 80 da LDB (Lei n 9.394/96). Brasília: Presidência da República. Disponível em: http://www.mec.gov.br/seed/tvescola/ftp/leis/D2494.doc. Acesso em: 23 out. 2020.

BRASIL DE FATO. Quem são as pessoas que não têm acesso à internet no Brasil?. Disponível em: https://www.brasildefato.com.br/2020/08/10/quem-saoas-pessoas-que-nao-tem-acesso-a-internet-no-brasil. Acesso em: 17 nov. 2020.

DE OLIVEIRA FONTES, Joaquim Jorgen. ProcrastENSINAÇÃO Classificação dos hábitos de procrastinação digital no ambiente académico de uma turma do $1^{\circ}$ ano de Design e criação de método curricular pedagógico autorregulador da aprendizagem. 2012. Disponível em: http://hdl.handle.net/10216/72685. Acesso em: 26 out. 2020. 
DUFFY, F. The ideology of supervision. In: FIRTH, G.; PAJAK; E. (Ed.). Handbook of research on school supervision. New York: MacMillan, 1998.

GARCIA, Tânia Cristina Meira; MORAIS, Ione Rodrigues Diniz; ZAROS, Lilian Giotto; RÊGO, Maria Carmem Freire Diógenes. Ensino remoto emergencial: proposta de desing para organização de aulas. Natal: SEDIS/UFRN, 2020, $18 p$.

GONDIM, Sônia Maria Guedes. Perfil profissional e mercado de trabalho: relação com a formação acadêmica pela perspectiva de estudantes universitários. Revista Estudos de Psicologia, Campinas, v. 7, n. 2, p. 299309, jul-dez. 2002.

IBGE. (Instituto Brasileiro de Geografia e Estatística. Pesquisa Nacional por Amostra de Domicílios (PNAD): Acesso à Internet e à Televisão e Posse de Telefone Móvel Celular para Uso Pessoal. Rio de Janeiro: IBGE, 2015.

KENSKI, Vani Moreira. Educação e tecnologias: o novo ritmo da informação. Campinas: Editora Papirus. 2012. p.141.

MAINART, D. A.; SANTOS, C. M. A importância da tecnologia no processo ensino-aprendizagem. In: CONGRESSO VIRTUAL BRASILEIRO DE ADMINISTRAÇÃO, 7, 2010. Anais, 2010.

OLIVEIRA, L.; MACHADO, L. Percepção, cognição, dimensão ambiental e desenvolvimento com sustentabilidade. In: VITTE, A.; GUERRA, A. (Orgs.): Reflexões sobre a Geografia Física no Brasil. Rio de Janeiro, Bertrand Brasil, 2004.

PEREIRA, Geiza Basualdo Bogado. O estudante de Ead (Ensino a Distância): um estudo de perfil e interação geracional. Dissertação de Mestrado em Administração/PPGA/UMESP. 2015, 133p.

POLATO, A. Um guia sobre o uso das tecnologias em sala de aula. Revista Nova Escola, n. 223, jun. 2009.

RIBEIRO, Elvira Nunes; MENDONÇA, Gilda Aquino de Araújo; MENDONÇA, Alzino Furtado. A IMPORTÂNCIA DOS AMBIENTES VIRTUAIS DE APRENDIZAGEM NA BUSCA DE NOVOS DOMÍNIOS DA EAD. 2007, $11 \mathrm{p}$.

ROSALES, G. C. M; MAGALINI, L. M. Planejamento, execução e avaliação de projetos educacionais. Caderno de Referência de Conteúdo. Batatais: Centro Universitário Claretiano, 2007.

SANCHO, Juana Maria; HERNÁNDEZ, Fernando. Tecnologias para transformar a educação. Porto Alegre: Artmed, 2006.

SCHOUWENBURG, H. Procrastination in Academic Settings: General Introduction. Em: Schouwenburg, H.;Lay,C; Timothy,P. Ferrari, J. (Orgs.) 
Counseling the Procrastinator in Academic Settings. American, Psychological Association, p.3-18, 2004.

SERAFINI, Alessandra M. S. A autonomia do aluno no contexto da Educação a Distância. 2012. Disponível em: <https://www.ufff.br/revistaedufoco/files/2013/05/artigo-031.pdf>. Acesso em: 26/10/2020.

TUAN, Y. F. Topofilia: Um estudo da percepção, atitudes e valores do meio ambiente. São Paulo, Difel, 1980.

VYGOTSKY, L. S. et al. Psicologia Pedagógica. São Paulo: Martins e Fontes, 2001. 516p.

YIN, R. K. Estudo de caso: planejamento e métodos. 3. ed. Porto Alegre: Bookman, 2005. 212 p.

Recebido: 29/10/2020

Aprovado: $26 / 11 / 2020$

Como citar: PAULO, J. R.; ARAÚJO, S. M. M. S.; OLIVEIRA, P. D. Reflexões sobre o processo educativo em tempos de pandemia através das percepções de pós-graduandos em educação.

Revista de Estudos e Pesquisas sobre Ensino Tecnológico (EDUCITEC), v. 6, Ed. Esp.

Desafios e avanços educacionais em tempos da COVID-19, e152520, 2020.

Direito autoral: Este artigo está licenciado sob os termos da Licença Creative Commons-

Atribuição 4.0 Internacional.

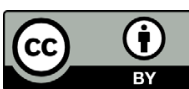

